\title{
Temperature Dependency of State of Charge Inhomogeneities and their Equalization in Cylindrical Lithium-Ion Cells
}

\author{
P. J. Osswald ${ }^{\mathrm{a}, \mathrm{b}, *}$, S. V. Erhard ${ }^{\mathrm{a}}$, A. Rheinfeld ${ }^{\mathrm{a}}$, B. Rieger ${ }^{\mathrm{a}}$, H. E. Hoster ${ }^{\mathrm{c}}$, \\ A. Jossen ${ }^{\mathrm{a}}$ \\ ${ }^{a}$ Institute for Electrical Energy Storage Technology (EES), Technical University of Munich \\ (TUM), Munich \\ ${ }^{b}$ TUM CREATE Ltd., Singapore \\ ${ }^{c}$ Energy Lancaster, Lancaster University, Lancaster
}

\begin{abstract}
The influence of cell temperature on the current density distribution and accompanying inhomogeneities in state of charge (SOC) during cycling is analyzed in this work. To allow for a detailed insight in the electrochemical behavior of the cell, commercially available 26650 cells were modified to allow for measuring local potentials at four different, nearly equidistant positions along the electrodes. As a follow-up to our previous work investigating local potentials within a cell we apply this method for studying SOC deviations and their sensitivity to cell temperature. The local potential distribution was studied during constant current discharge operations for various current rates and discharge pulses in order to evoke local inhomogeneities for temperatures ranging from $10{ }^{\circ} \mathrm{C}$ to $40{ }^{\circ} \mathrm{C}$. Differences in local potentials were considered for estimating local SOC variations within the electrodes. It could be observed, that even low currents such as $0.1 \mathrm{C}$ can lead to significant inhomogeneities, whereas a higher cell temperature generally results in more pronounced inhomogeneities. A rapid SOC equilibration can be observed if the variation in the SOC distribution corresponds to a considerable potential difference defined by the open circuit voltage of either the positive or negative electrode. With increasing temperature, accelerated
\end{abstract}

\footnotetext{
${ }^{*}$ Corresponding author

Email address: pjo@tum.de (P. J. Osswald)
}

Preprint submitted to Journal of Power Sources

September 6, 2016 
equalization effects can be observed.

Keywords: Lithium-ion battery, current density distribution, local potential measurements, SOC inhomogeneity, temperature dependency

\section{Introduction}

The steady increase in energy and power density combined with continuous improvements regarding cycle life and safety extended the application field of lithium-ion batteries (LIB) from consumer electronics towards hybrid and full electric vehicles. To deliver the necessary amount of energy, the packing density in already available cells has been significantly increased [1] and larger cells with advantages regarding energy density have been introduced.

Finding the right operation condition for the usage and charging of the battery is a crucial requirement for a long cycle life and a safe operation [2]. Low temperatures decrease the performance of the cell [3] and improve the risk of lithium deposition on the anode during the charging process [4]. On the contrary, high temperatures foster unwanted side reaction, increasing the thickness of solid electrolyte interphase (SEI) and causing a loss in the capacity and power capability of the cell $[5,6]$. Variations in the current density distribution in the cell lead to additional heat generation $[7,8,9]$ and consequently to uneven aging effects throughout the cell [10].

A cell design, which assures uniform utilization of the electrodes, is desirable for any battery. But in terms of cost savings and weight reduction, only few tabs are used within considerably long electrode wraps with a length up to meters. This can lead to a restricted representation of the electrode's behavior at the cell's terminal. To define the optimal operating conditions of the cell, detailed knowledge of the effects leading to SOC and state of health ( $\mathrm{SOH})$ inhomogeneities in the cell is necessary.

Studies on the impact of current and temperature on inhomogeneities in the current density during cycling have been performed by Zhang and co-workers using a custom made cell with ten individually accessible positive electrode layers 
and a single negative electrode. With this approach, they can resolve the current density distribution between several compartments of the cell and measure them directly by additional shunt resistors. Neglecting inhomogeneities arising from the manual production process, this method gives deep insights into the current density distribution within a cell. They studied C-rates ranging from $\mathrm{C} / 5$ up to $4 \mathrm{C}$ [11], also using different tab patterns [12]. Similar to the setup presented here, a LFP/graphite chemistry is investigated with an electrode thickness of about $65 \mu \mathrm{m}$ for LFP and about $40 \mu \mathrm{m}$ for graphite. In sum, their cell exhibits a length of $1.8 \mathrm{~m}$, which is in accordance with our experimental setup (approx. $1.6 \mathrm{~m}$ ). They reported significant SOC variations during discharge up to $20 \%$ at the end of a $2 \mathrm{C}$ discharge operation at $21^{\circ} \mathrm{C}$. Further, they highlighted balancing currents occurring during relaxation periods. In their work they refer to a submitted paper for an analysis of the relaxation currents, which we were not able to find. Although the setup presented here is not capable of measuring currents directly, the local potentials can be used as an indicator for a current and SOC distribution. As a subsequent step to previous studies, recent results regarding the SOC variations within a cell due to dynamic current pulses as well as varying ambient temperatures are presented in this work by investigating local potentials in modified commercial cells.

In our previous study, the modification process and the long-term performance of the investigated cell has been presented [13]. In combination with a detailed multi-dimensional physico-chemical model, the inner states such as lithium concentration and heat generation were simulated, matching the experimental results accurately [14]. Furthermore, it has been shown that the current density distribution under alternating current (ac) conditions shows a high temperature dependency accompanied with an observed strong attenuation along the current collectors [15].

This work will focus on the impact of different operating temperatures on the cell's electrical and electrochemical performance and their effect on local SOC inhomogeneities during static and dynamic load profiles. Both the development of SOC inhomogeneities and the accompanied equilibration processes 
after switching off the current are investigated by the means of local potential measurements.

\section{Experimental work}

The cell used in this work is a commercial 26650 cylindrical $\mathrm{LiFePO}_{4}$ / graphite cell with a nominal capacity of $2.5 \mathrm{Ah}$. In its original state, the cell exhibits four negative and four positive internal current tabs, which are spot welded to the respective cell terminal. Opening the cell as exemplary illustrated in Fig. 1 a) and b) for the cathode side allowed the separation of these tabs during the modification process and made each current tab accessible individually. The modification process and cell parameters have been published in our previous work in more detail [13]. It has been demonstrated, that the modification process has negligible impact on the electrochemical performance of the cell during measurement in both time [13] and frequency domain [15]. The almost equidistant position of the current tabs as shown in Fig. 1 c) allows for a symmetric operation of the cell. A current terminal $T_{m n}$ with the respective terminal voltage $U_{T m n}$ is defined by one current tab of the anode $\left(A_{m}\right)$ and one of the cathode $\left(C_{n}\right)$ with $m, n \in\{1 ; 4\}$. As cylindrical cells are used, the two outermost current tabs $C_{1}$ and $A_{1}$ are defined as terminal $T_{11}$ and the two innermost tabs $C_{4}$ and $A_{4}$ are defined as terminal $T_{44}$, as illustrated schematically in Fig. $1 \mathrm{c}$ ).

In the first set of experiments, the focus is laid on the variation of current density distribution for $0.1,0.5,1$. and $2 \mathrm{C}$ discharge rates and the impact of different ambient temperatures $\left(10,20,30\right.$, and $\left.40^{\circ} \mathrm{C}\right)$ prevailing during operation. The cell temperature was controlled by a Memmert IPP200 incubator. To monitor the heat generation during cycling, an external as well as an internal T-type thermocouple was attached to and placed inside the cell center, respectively. Tab. 1 gives an overview of the applied measurement sequence. Prior to the measurement, the climate chamber temperature was adjusted and the cell was placed inside for $2 \mathrm{~h}$ to equilibrate. A BaSyTec CTS system was used 

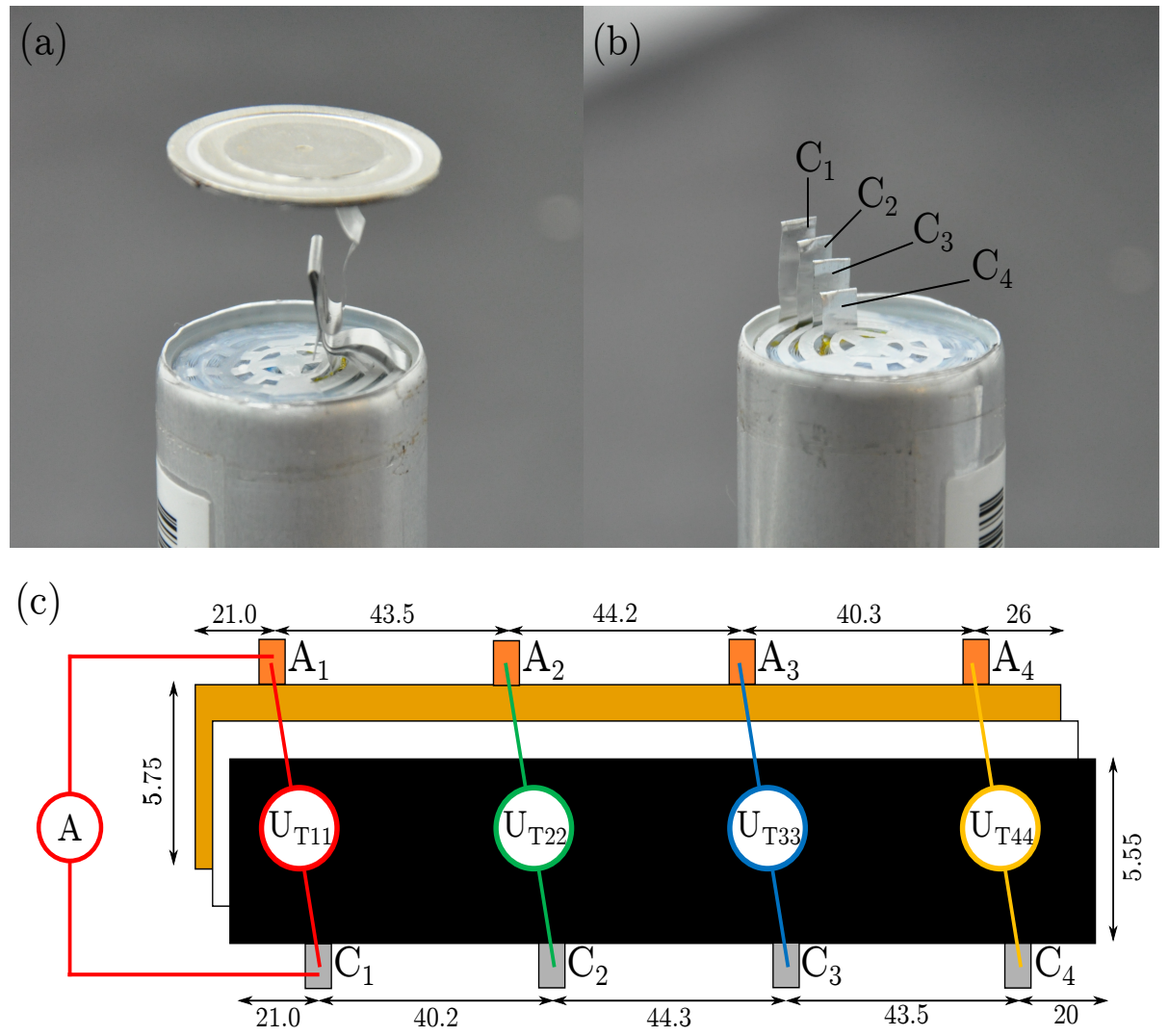

Figure 1: Opened cell with original tab arrangement prior (a) and after separation (b) during the modification process. In (c), a sketch of the used operation mode and the cell geometry with dimensions in $\mathrm{cm}$ is displayed 
for cycling. For charging the cell between each discharge step, the tab configuration was switched to $A_{2} \& A_{4}$ and $C_{1} \& C_{3}$ and a constant current constant voltage $(\mathrm{CCCV})$ charging protocol with $\mathrm{I}_{\text {charge }}=0.2 \mathrm{C}$ and $\mathrm{U}_{\text {cutoff }}=3.6 \mathrm{~V}$ was applied. The asymmetrical tab combination, accessing two cathode and two anode tabs together with the applied CV phase was regarded to guarantee a homogeneous SOC distribution after the charging step; a crucial prerequisite for the subsequent measurements. The charging step was followed by a relaxation phase of $30 \mathrm{~min}$ to allow for the equilibration of possible temperature and concentration gradients across the electrodes. To discharge the cell, only terminal $T_{11}\left(A_{1}-C_{1}\right)$ was used and currents of $0.1,0.5,1$, and $2 \mathrm{C}$ were applied to this terminal configuration. In addition to the BaSyTec battery tester, an Agilent 34972 with a 20 channel multiplexer was used for supplementary voltage measurements at the terminals $T_{22}, T_{33}$, and $T_{44}$ during the discharge process. It is worth mentioning, that all charge processes have not been performed at the same temperature. Instead, the charge temperature was the same as the discharge temperature. Despite the different temperatures, the high power capability of the cell as well as the slow charging current resulted in only negligibly small capacity differences during the charge processes at 10 and $40^{\circ} \mathrm{C}$.

In the second set of experiments, the equilibration processes along the electrode and their temperature dependency are investigated. The applied measurement sequence is described in Tab. 2. The cell was again fully charged following the same CCCV protocol and tab configuration as described followed by a consecutive stepwise discharge by means of and intermittent $1 \mathrm{C}$ current rate, applied at terminal $T_{11}$. The discharge pulses of $1 \mathrm{C}$ for 3 min resulted in a SOC change of approximately $5 \%$ and, hence, 20 discharge-relaxation steps were conducted until the cell was fully discharged. Between each discharge step, a relaxation period of 117 min was included to examine the transient voltage evolution at the four different positions along the electrodes. At the end of the $40 \mathrm{~h}$ measurement sequence, the temperature was adjusted and the cell was recharged. In accordance with the continuous discharge current measurements (sequence \#1) the intermittent discharge current measurements (sequence \#2) 
Table 1: Measurement sequence 1 with varying continuous discharge currents, repeated for $10,20,30$, and $40^{\circ} \mathrm{C}$

\begin{tabular}{lll} 
Mode & Tab arrangement & Parameters \\
\hline Temperature & & $2 \mathrm{~h}$, repeat for \\
adjustment & & $10,20,30,40^{\circ} \mathrm{C}$ \\
Charge CCCV & $A_{1} \& A_{3}-C_{2} \& C_{4}$ & $0.2 \mathrm{C} / \mathrm{CV}$ \\
Rest & & $30 \mathrm{~min}$ \\
Discharge CC & $A_{1}-C_{1}$ & $0.1 \mathrm{C}$ \\
Charge CCCV & $A_{1} \& A_{3}-C_{2} \& C_{4}$ & $0.2 \mathrm{C} / \mathrm{CV}$ \\
Rest & & $30 \mathrm{~min}$ \\
Discharge CC & $A_{1}-C_{1}$ & $0.5 \mathrm{C}$ \\
Charge CCCV & $A_{1} \& A_{3}-C_{2} \& C_{4}$ & $0.2 \mathrm{C} / \mathrm{CV}$ \\
Rest & & $30 \mathrm{~min}$ \\
Discharge CC & $A_{1}-C_{1}$ & $1 \mathrm{C}$ \\
Charge CCCV & $A_{1} \& A_{3}-C_{2} \& C_{4}$ & $0.2 \mathrm{C} / \mathrm{CV}$ \\
Rest & & $30 \mathrm{~min}$ \\
Discharge CC & $A_{1}-C_{1}$ & $2 \mathrm{C}$
\end{tabular}


Table 2: Measurement sequence 2 with $201 \mathrm{C}$ discharge steps, repeated for 10, 20, 30, and $40^{\circ} \mathrm{C}$

\begin{tabular}{lll} 
Mode & Tab arrangement & Parameters \\
\hline Temperature & & $2 \mathrm{~h}$, repeat for \\
adjustment & & $10,20,30,40^{\circ} \mathrm{C}$ \\
Charge CCCV & $A_{1} \& A_{3}-C_{2} \& C_{4}$ & $0.2 \mathrm{C} / \mathrm{CV}$ \\
Rest & & $30 \mathrm{~min}$ \\
Discharge CC & $A_{1}-C_{1}$ & $1 \mathrm{C} / 3 \mathrm{~min}, 20 \mathrm{x}$ \\
Relaxation & $T_{11}, T_{22}, T_{33}, T_{44}$ & $117 \mathrm{~min}, 20 \mathrm{x}$
\end{tabular}

were carried out for $10,20,30$, and $40^{\circ} \mathrm{C}$.

\section{Results and Discussion}

\subsection{Current density distribution}

As described in the previous section, the cell was discharged by applying current to terminal $T_{11}\left(A_{1}-C_{1}\right)$ only. The voltage was measured at the currentcarrying terminal and at three additional equidistant positions along the electrode. Fig. 2 exemplarily shows the discharge voltage of the cell for $0.1 \mathrm{C}$ at $10^{\circ} \mathrm{C}$ and $40^{\circ} \mathrm{C}$. To accentuate the four different potential curves, the discharge profile is shown within a voltage range from 3.35 to $3.15 \mathrm{~V}$ instead of the full discharge range from 3.6 to $2 \mathrm{~V}$. The characteristic features of the cell's transient potential profile are highlighted with $(\mathrm{A}),(\mathrm{B})$ and $(\mathrm{C})$ in Fig. 2 b). The differential voltage analysis (DVA) [16] for the two terminal voltages $U_{T 11}\left(10^{\circ} \mathrm{C}\right)$ and $U_{T 11}\left(40^{\circ} \mathrm{C}\right)$ is displayed in Fig. $\left.2 \mathrm{c}\right)$. The local minimum around $70(\mathrm{~A})$ and $30 \%$ SOC (C) were identified to result from the phase transitions in the graphite anode [17]. The cathode active material $\mathrm{LiFeP}_{4}$ does not feature any phase transitions and exhibits an almost flat voltage profile over a large lithiation range [18]. It is observed that the phase transitions in the graphite anode are more pronounced for higher temperatures.

The differences between the potential at the current-carrying terminal $U_{T 11}$ 
Figure 2: Cell voltage $U_{T 11}$ and additional potential measurements $U_{T 22}, U_{T 33}$, and $U_{T 44}$ along the electrode during a $0.1 \mathrm{C}$ discharge at $10^{\circ} \mathrm{C}$ (a) and $40^{\circ} \mathrm{C}$ (b) and the resulting differential voltage $\mathrm{dVdQ}$ at Terminal $T_{11}$ for both temperatures (c)
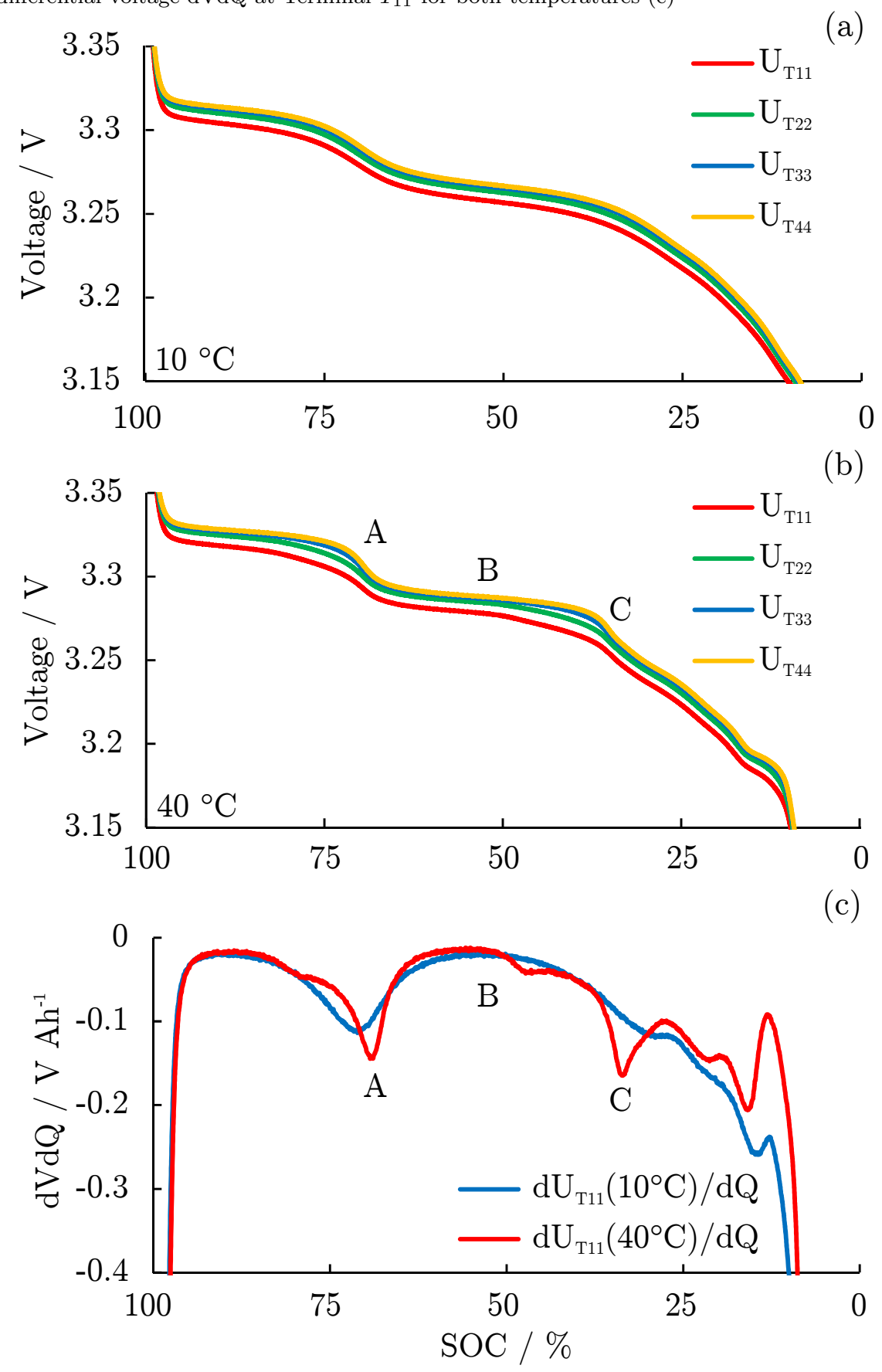
and the other terminals are displayed by the curves $\Delta U_{T 11-T 22}, \Delta U_{T 11-T 33}$, and $\Delta U_{T 11-T 44}$ in Fig. 3. The values are illustrated for the $0.1 \mathrm{C}$ discharge at 10 (a) and $40^{\circ} \mathrm{C}(\mathrm{b})$. An increase in the potential difference is attributed to a rising difference in the degree of lithiation within the electrode, resulting from the OCV of the used electrode materials. The graphite anode dominates the cell's potential characteristics, therefore the minima in (A) and (C) occur, as soon as graphite close to current carrying tab exhibits a higher potential as graphite close to the measurement tab [13]. This potential difference is related to inhomogeneities in the SOC along the electrode.

At $10^{\circ} \mathrm{C}$ (Fig. 3 a), a small shift of the position of the minimum in (C) towards lower SOCs can be observed with increasing distance to the current carrying terminal. This agrees well with the suggested explanation, as the deliatihation of the graphite begins near the current carrying tab and pursues along the electrode towards the cell center. This effect is also observed in Fig. 3 b) at $40^{\circ} \mathrm{C}$, where the differences in the position can be clearly distinguished for the first minimum (A). The SOC values are $74.7 \%$ for $\Delta U_{T 11-T 22}$ and $72.1 \%$ for $\Delta U_{T 11-T 44}$. These values are used to calculate the SOC difference $\Delta \mathrm{SOC}_{\min A}=2.6 \%$. With progressing discharge, a shift in the position of the second minimum is also observed. The minima occur at $41.7 \%$ for $\Delta U_{T 11-T 22}$ and at $37.4 \%$ for $\Delta U_{T 11-T 44}$. Extracting the position of the minima from the measurement data for all four temperatures leads to Fig. 4, where the SOC differences $\triangle S O C_{\min A}$ and $\triangle S O C_{\min C}$ are displayed.

The SOC difference at position $(\mathrm{A})$ is smaller as in $(\mathrm{C})$, suggesting an increase in the inhomogeneity with progressing discharge. This corresponds well to the findings of Zhang et al. [11], as they observe an increasing SOC inhomogeneity throughout discharge. Only when the average SOC is less than about $5 \%$, the slope of the SOC gradient throughout the cell flattens, since the current density changes significantly. At $10^{\circ} \mathrm{C}$, the differences in the $\mathrm{SOC}$ are small with approximately $0.5 \%$ and $1 \%$, but increase with increasing temperature. At $40{ }^{\circ} \mathrm{C}$, the difference reaches up to $\Delta \mathrm{SOC}_{\operatorname{minC}}=4.3 \%$ at $(\mathrm{C})$. These findings lead to the conclusion that even discharge currents as low as $0.1 \mathrm{C}$ can lead to 

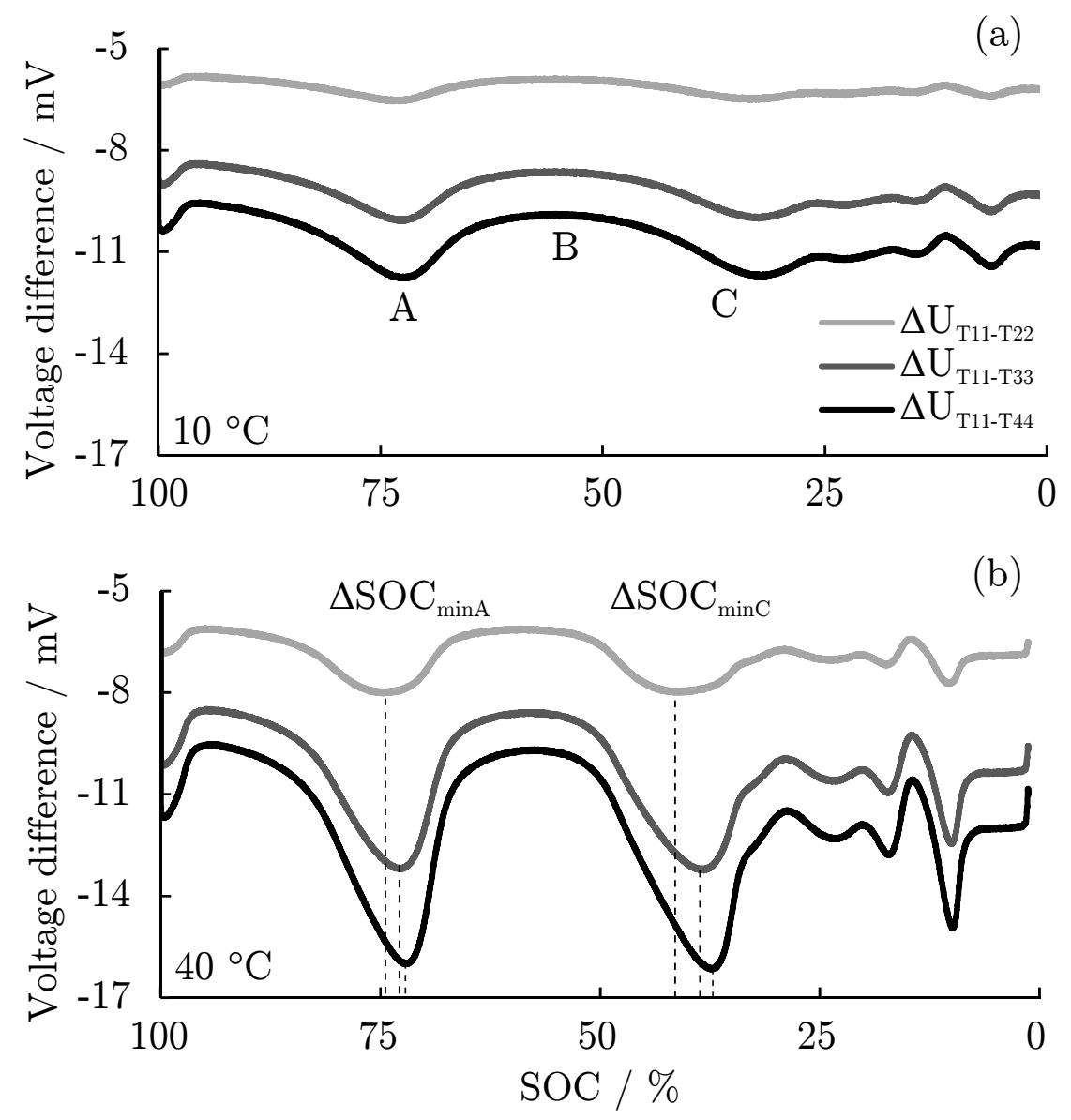

Figure 3: Potential difference between the current terminal $T_{11}$ and the measurement terminal $T_{22}, T_{33}$, and $T_{44}$ at $10^{\circ} \mathrm{C}$ (a) and $40^{\circ} \mathrm{C}$ (b) during a $0.1 \mathrm{C}$ discharge 


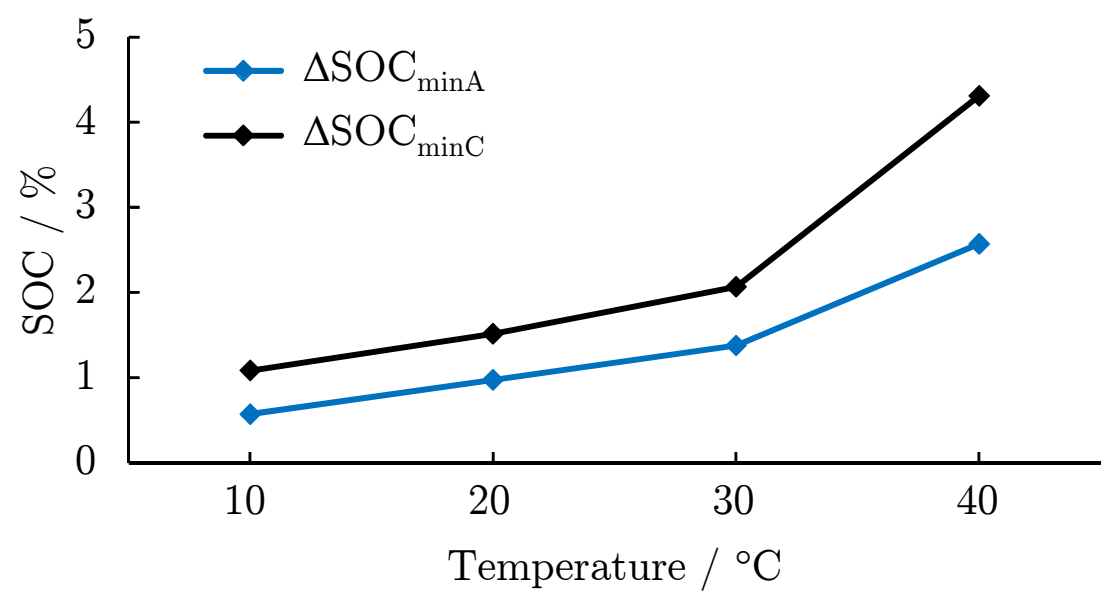

Figure 4: SOC difference between position of minima (A) and (C), depending on cell temperature during a $0.1 \mathrm{C}$ discharge

significant inhomogeneities in the SOC distribution along the electrodes with a clear tendency to larger differences with increasing temperature and discharge time. This relation might be transferred to higher current densities, following the same trend. Due to the design restrictions of the cell setup, currents higher than $0.5 \mathrm{C}$ lead to measurable thermal gradients superimposing the electrical signal [19].

With increasing terminal distance, an increase in the local potential difference is observed. Therefore, the focus in this work is laid on the potential difference $\Delta U_{T 11-T 44}$ as the distance of $128 \mathrm{~cm}$ between the two terminals leads to the largest observable signal. In Fig. 5 a) the calculated potential differences $\Delta U_{T 11-T 44}$ at four different temperatures are displayed. An initial IR drop of approximately $9.7 \mathrm{mV}$ is observed for all temperatures.

Both local minima become more pronounced with increasing temperature. The voltage difference $\Delta V$ between the voltage plateau and the first local minimum (A) at $10^{\circ} \mathrm{C}$ is measured to be $2.2 \mathrm{mV}$ which increases to $6.3 \mathrm{mV}$ for $40^{\circ} \mathrm{C}$ as indicated in Fig. 5 a). Similar to the previously described shift of the second minima $(\mathrm{C})$ due to the larger distance to the current tab, a shift towards 
lower SOCs is observed for lower temperatures. The minimum (C) occurs for $10{ }^{\circ} \mathrm{C}$ at $33 \%$ and for $40^{\circ} \mathrm{C}$ at $36 \%$ SOC, which represents a time difference of $\Delta t=18 \mathrm{~min}$ for the applied $0.1 \mathrm{C}$ discharge rate. Changes in the slope of the cell voltage during the phase transition as shown in Fig. 2 are assumed to be responsible for this shift, indicating that the largest inhomogeneity can occur at different SOCs for different temperatures. Enhanced kinetics, electrolyte conductivity and diffusivity within the cell based on an increasing temperature lead to an inhomogeneous utilization of the active material. This effect is even further pronounced, as the resistance of the current collectors increase with increasing temperature due to the positive temperature coefficients of resistance for copper $\left(\alpha_{C u}=3.93 \times 10^{-3} \mathrm{~K}^{-1}\right)$ and aluminum $\left(\alpha_{A l}=4 \times 10^{-3} \mathrm{~K}^{-1}\right)$. The applied temperature difference $\Delta T=30^{\circ} \mathrm{C}$ leads to a resistance increase of approximately $12 \%$ for both current collectors in this case.

As reaction kinetics and material properties such as electrolyte conductivity, diffusion coefficients in electrolyte and active material vary on a large scale with temperature [20, 21], special focus was laid on avoiding any side effects based on temperature gradients within the cell. The temperature profile in Fig. 5 b) shows the difference between the measured temperature inside the cell center and measured ambient temperature of the used climate chamber. As the chosen current of $0.1 \mathrm{C}$ is low, no significant increase in the cell temperature is observed for the different test scenarios and a maximum temperature increase of only $0.6 \mathrm{~K}$ is measured at the end of the discharge operation.

Fig. 6 illustrates the potential differences $\Delta U_{T 11-T 44}$ for various temperatures during a discharge at $0.5 \mathrm{C}$ (a) and the resulting temperature increase (b). The initial IR drop of $9 \mathrm{mV}$ at $0.1 \mathrm{C}$ almost linearly increases due to the higher current to $40 \mathrm{mV}$ at $0.5 \mathrm{C}$. Whereas the potential differences for the $0.1 \mathrm{C}$ discharge operation showed nearly the same transient behavior between $95 \%$ and $85 \%$ SOC, the values for $0.5 \mathrm{C}$ differ within this range. The measurement performed at $40^{\circ} \mathrm{C}$ exhibits the lowest potential difference in the beginning of the discharge operation, whereas the measurement at $10^{\circ} \mathrm{C}$ shows the highest. At $85 \%$ SOC, all curves cross and the $40^{\circ} \mathrm{C}$ curve exhibits the largest potential 

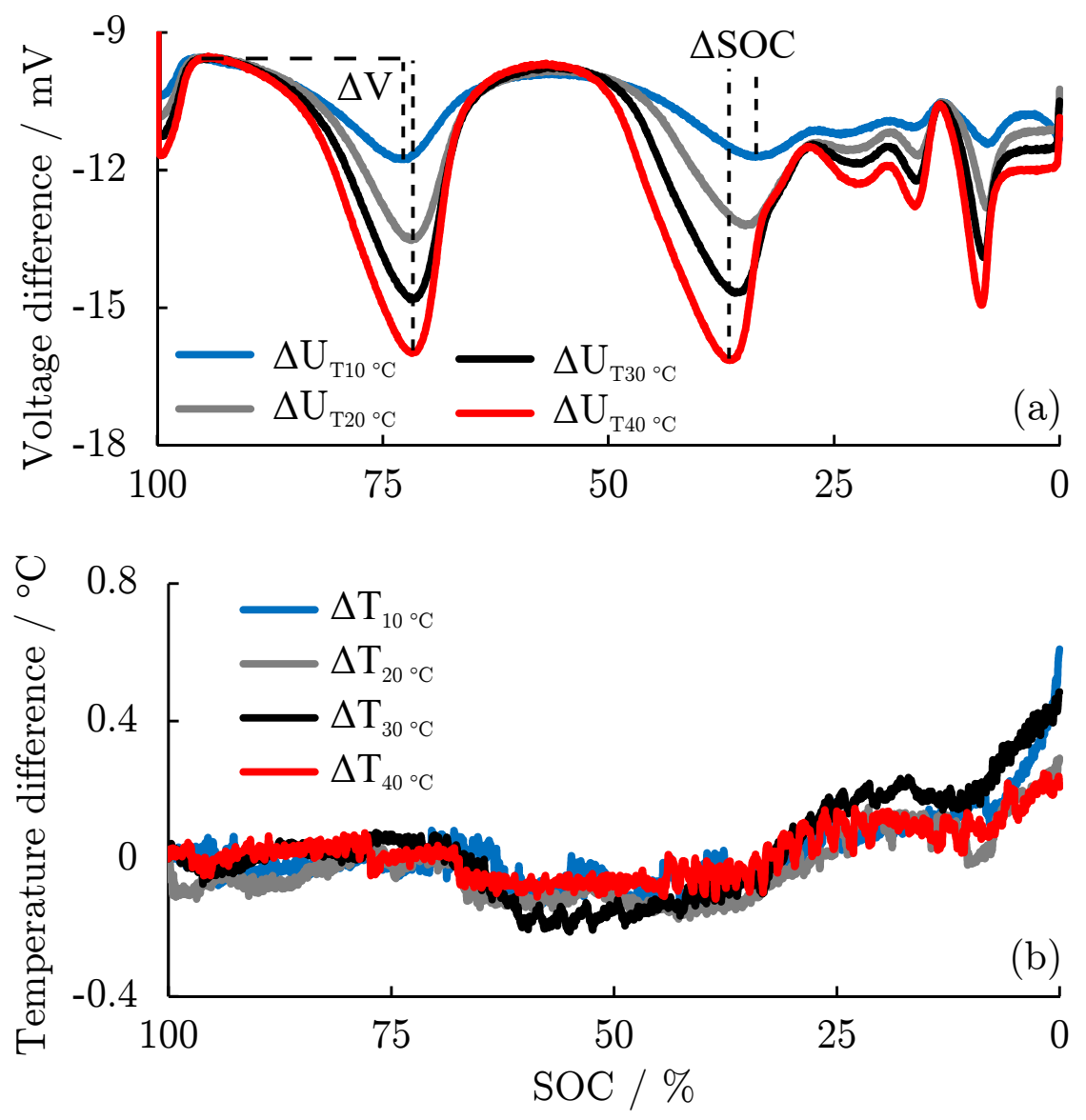

Figure 5: Voltage difference between terminal $T_{11}$ and terminal $T_{44}$ at different temperatures (a) and temperature difference between cell center and climate chamber during a discharge of $0.1 \mathrm{C}(\mathrm{b})$ 
difference for the rest of the discharge process.

We can derive from these results, that the potential drop along the current collectors dominates the characteristics in the very beginning of the discharge operation shown by the variation in the initial IR drop due to the aforementioned positive temperature coefficient of resistance. At a discharge rate of $0.5 \mathrm{C}$, we can observe that the aforementioned enhanced kinetics and transport properties at higher temperatures result in a larger current close to the terminal T11 in the range between $95 \%$ and $85 \%$ SOC. With decreasing SOC, the potential difference due to a gradient in the degree of lithiation becomes more dominant and the area of utilized active material is shifted towards the cell center. When the majority of the graphite transforms from stage 1 to stage 2 , the deviation between the potential differences becomes smaller, and the active material close to the current terminal is again mainly utilized due to the potential drop along the current collectors. This effect occurs a third and a fourth time for the SOC range around $20 \%$ and $0 \%$, respectively.

The potential difference does not return to the initial value as observed for the $0.1 \mathrm{C}$ discharge, indicating a beginning of limitation in the diffusion processes and a resulting higher inhomogeneity of current densities within the electrodes. The second minimum becomes less pronounced, especially at lower temperatures. This second minimum is located around SOC values of $26.4 \%$ for $40{ }^{\circ} \mathrm{C}$ and $17.6 \%$ for $10^{\circ} \mathrm{C}$ as indicated by the dashed lines in Fig. 6. Therefore, $\Delta$ SOC increases from $3 \%$ at $0.1 \mathrm{C}$ to $8.8 \%$ at $0.5 \mathrm{C}$.

The generated heat during the discharge process raises the temperature at the cell center by $<1 \mathrm{~K}$ compared to the climate chamber for $75 \%$ of the SOC range. Towards the end of the discharge, the temperature difference $\Delta T$ increases to a maximum of $4 \mathrm{~K}$ for the measurement at $10^{\circ} \mathrm{C}$ as shown in Fig. 6 b). Measurements performed at higher ambient temperatures show a lower increase towards the end due to the reduced charge transfer overpotentials of the cell. Based on these results, the effect of temperature rise on the electrochemical behavior is considered to be negligible for a discharge current of 0.5C. Experiments at higher $\mathrm{C}$-rates $(1 \mathrm{C}, 2 \mathrm{C}$ ) resulted in a significantly stronger increase in 

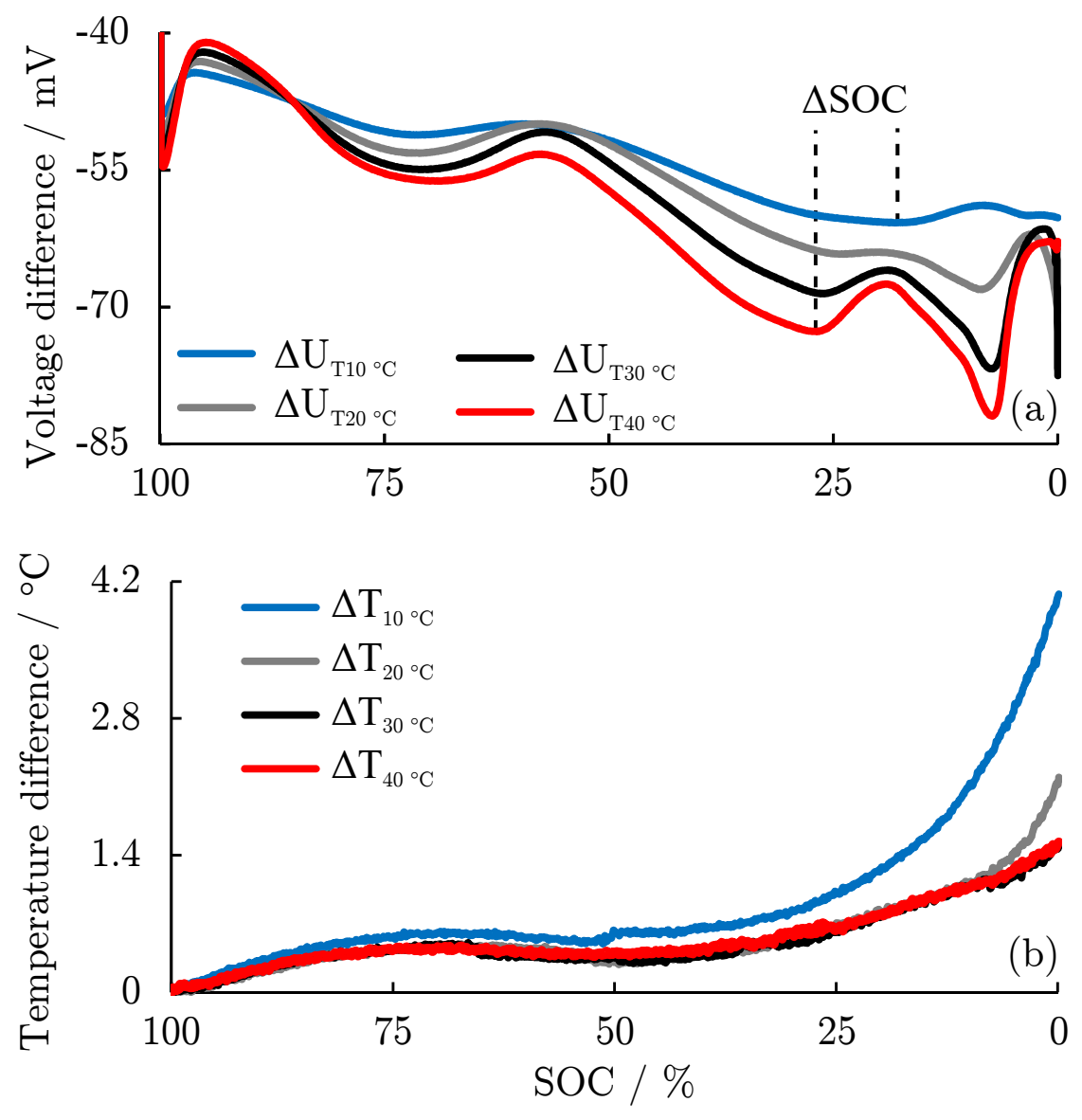

Figure 6: Voltage difference between terminal $T_{11}$ and terminal $T_{44}$ at different temperatures (a) and temperature difference between cell center and climate chamber during a discharge of $0.5 \mathrm{C}(\mathrm{b})$ 
cell center temperature of up to $8 \mathrm{~K}$ and $12 \mathrm{~K}$. With these strong temperature gradients inside the cell, a separation of electrochemical and thermal effects is no longer possible and the results for higher currents of $1 \mathrm{C}$ and $2 \mathrm{C}$ are therefore omitted. Consequently, measurements at the investigated cylindrical cells seem to be limited to constant discharge currents of $0.5 \mathrm{C}$. To allow for a better separation of the effects, improved measurements on single layer pouch cells with better cooling capabilities are under investigation and will be published soon.

\subsection{Voltage equalization}

The modified cell can be considered as a parallel configuration of four cells, whereas each current terminal allows the measurement of a single cell. The major difference is that the cells are not only electrically but also ionically and thermally connected. In an equilibrated state, all four connected cells possess the same potential. Disturbances of the equilibrium will lead to equalization processes between the terminals until the voltage difference approaches zero [22]. To investigate the time scale of these equilibrating processes, the cell was fully charged as described in Tab. 2. The stepwise discharge using only terminal $T_{11}$ with a current of $1 \mathrm{C}$ resulted in 20 discharge steps with a SOC reduction of $5 \%$ per step.

In Fig. 7 the exemplary voltages of the current carrying terminal $U_{T 11}$ and the observing terminal $U_{T 44}$ during the measurement at $10{ }^{\circ} \mathrm{C}$ are displayed. In addition, the temperature of the cell center is plotted. During discharge, the cell temperature increases by $<1 \mathrm{~K}$ during the first sixteen steps and $<1.5 \mathrm{~K}$ during the last four steps. For measurements at higher ambient temperatures, the increase is even smaller, as the overall cell impedance decreases with increasing temperature. Due to this small temperature change, the effect of a temperature gradient on the electrochemical performance of the cell is considered to be neg-

ligibly small. Five characteristic SOCs have been investigated in more detail as highlighted in Fig. 7.

For SOCs around $90 \%$ and $60 \%$, a voltage plateau is observed as both electrodes exhibit a flat voltage curve for a certain range of lithiation. In the 


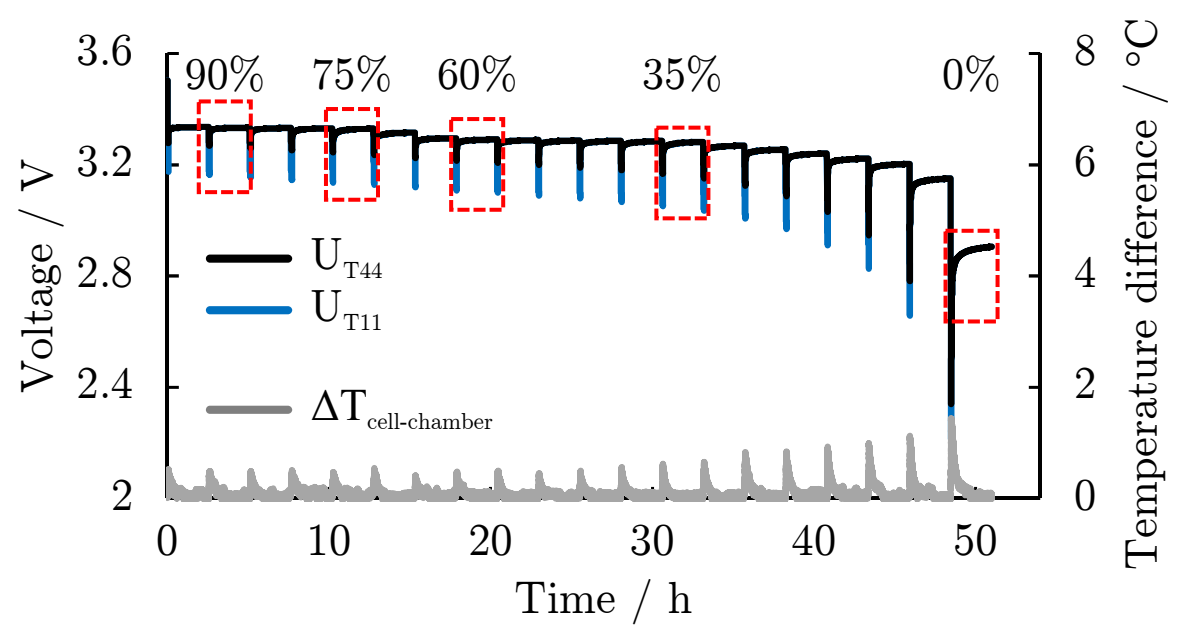

Figure 7: Voltage profile of $U_{T 11}$ and $U_{T 44}$ during measurement sequence 2 with highlighted SOCs and the temperature difference between climate chamber and cell center, performed at $10^{\circ} \mathrm{C}$

SOC ranges around $75 \%$ and $35 \%$, the anode shows a phase transformation and therefore a step in the voltage profile can be observed. For the last SOC at $0 \%$, both electrode voltages change significantly with the lithium content.

Fig. 8 compares the voltage equalization process inside the cell for different SOCs at $10^{\circ} \mathrm{C}(\mathrm{a})$ and $40^{\circ} \mathrm{C}(\mathrm{b})$. The equilibration process at $0 \% \mathrm{SOC}$ is completed within minutes. The steep gradient in the voltage profiles of both electrodes eliminates the local inhomogeneities during the discharge and nearly no equilibration along the electrodes needs to take place. Furthermore, local differences in the lithiation degree lead to large local potential differences, acting as a driving force for a fast equilibration process.

The potential difference measured for the two SOCs at $90 \%$ and $60 \%$ disappears within minutes. The absence of a potential difference as the major driving force leads to the conclusion that the local SOCs are not equilibrated during the relaxation period and the SOC inhomogeneities remain in the cell until diffusion processes are taking place along the electrode which, however, cannot be observed within the potential measurement. The expected time scale for a dif- 


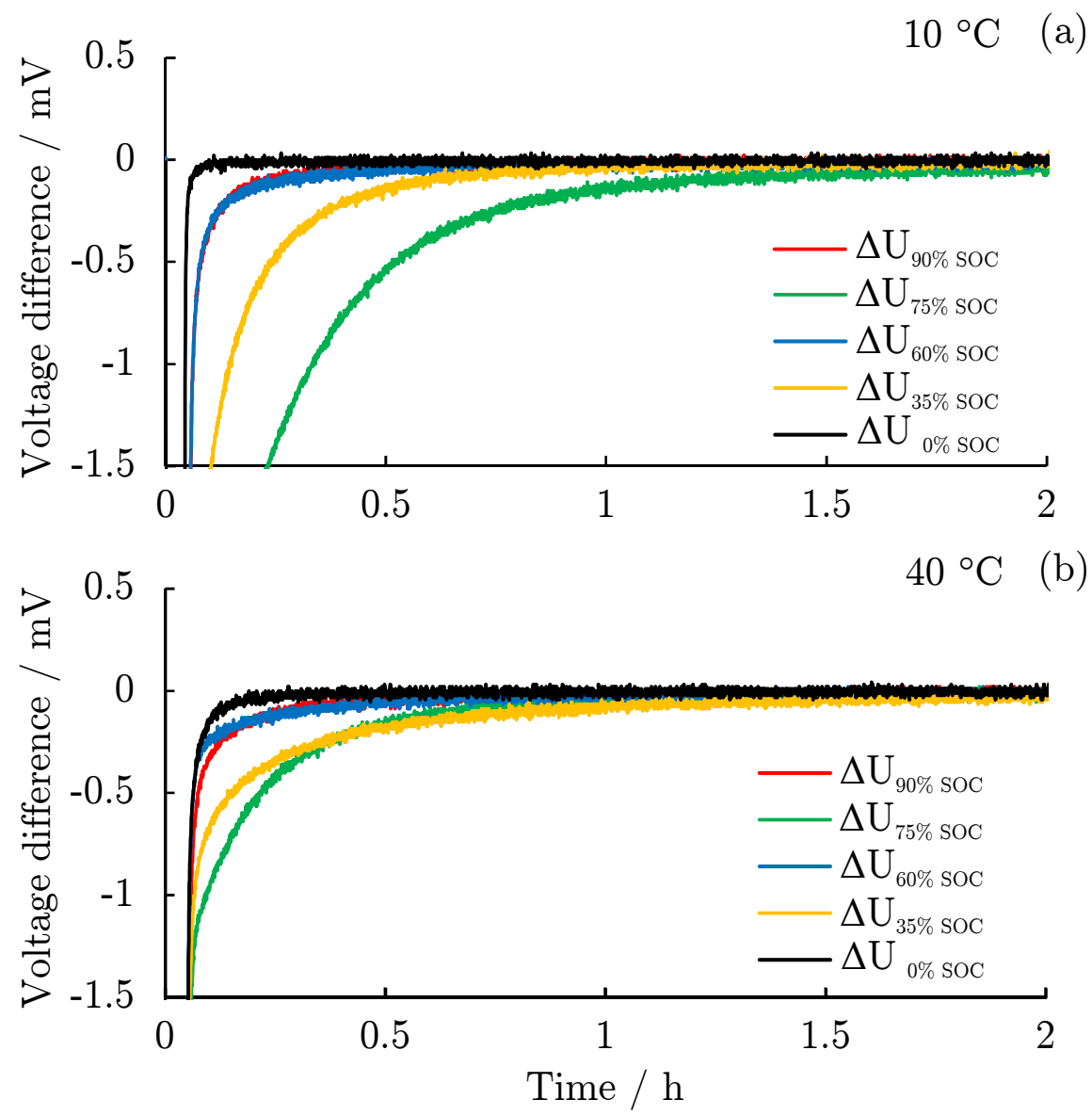

Figure 8: Voltage difference $\Delta U_{T 11-T 44}$ during 117 min relaxation period for 10 (a) and $40^{\circ} \mathrm{C}$ (b) at different SOCs 
fusion driven equilibration process is much larger [23]. A minor difference in the equilibration speed between the two SOCs is observed at higher temperatures.

The voltage difference $\Delta U_{T 11-T 44}$ for the SOCs around the graphite phase transition requires $90 \mathrm{~min}(75 \%)$ and $45 \mathrm{~min}(35 \%)$ to equilibrate. The induced voltage difference between the terminals is larger for the lower SOCs due to the steeper gradient in the graphite voltage profile. This indicates that despite a larger inhomogeneity, the steeper gradient in the voltage profile is the dominating force and the equilibration process elapses faster. Comparing the relaxation behavior for the two temperatures, it is observed that despite the higher SOC inhomogeneities for higher temperatures, the advanced electrochemical performance of the cell at this temperature leads to a faster voltage equalization process especially at $75 \%$ SOC.

\section{Conclusion}

The scope of this work was to investigate the temperature dependency of local SOC inhomogeneities in cylindrical lithium-ion cells and their equilibration processes after the current was switched off. Local potential measurements at four nearly equidistant positions along the electrodes of modified $26650 \mathrm{LiFePO}_{4}$ / graphite cells were performed for temperatures between $10^{\circ} \mathrm{C}$ and $40^{\circ} \mathrm{C}$ and either constant current discharge rates up to $0.5 \mathrm{C}$ or step wise discharge operations at $1 \mathrm{C}$. The constant current measurements were limited to currents of about $0.5 \mathrm{C}$, as the considerable heat generation for higher currents leads to a significant temperature gradient within the cell and, hence, an undesirable interference of the overall cell temperature with local temperature gradients.

Gained results from the measurements generally indicate larger SOC inhomogeneities for increasing cell temperatures and higher currents. Enhanced kinetic and transport properties such as lithium-ion diffusion in the active material or enhanced lithium-ion transport through the electrolyte allow a higher utilization degree of the active material close to the current collecting tab especially at the beginning of the discharge step. This is further superimposed by 
an increase of current collector resistance with rising temperature and the ac-

companying voltage drop along the current collector. Local SOC differences of up to $1.08 \%$ for $10^{\circ} \mathrm{C}$ and $4.3 \%$ for $40{ }^{\circ} \mathrm{C}$ even at low current rates such as $0.1 \mathrm{C}$ were observed. In case of the experimental cells, the phase transitions of the anode material and the resulting voltage plateaus and voltage steps in the open circuit voltage (OCV) dominated the course of the SOC inhomogeneities. The SOC range at which the largest inhomogeneities occur varies with temperature and decreases towards lower SOCs with decreasing temperature.

Experiments to investigate the equilibration processes after local disturbances of the SOC distribution were performed. Current pulses of $1 \mathrm{C}$ were applied to force local inhomogeneities during the discharge process. Measurements of the potential differences between the different positions and the observation of the equalization process indicate that local SOC inhomogeneities are only equilibrated, if the difference in the SOC corresponds to a potential difference defined by the OCV of either the positive or negative electrode. At SOC values showing a voltage plateau within the OCV of the anode and cathode (e.g. $90 \%$ and $60 \%$ SOC), nearly no potential equalization processes can be measured and the local SOC inhomogeneities remain until they become equilibrated due to diffusion processes.

Future work will address the cell design for local potential measurements generally, whereby a multi-tab cell design with a single-layered pouch cell is characterized. By that, we try to give a more quantitative analysis of relative potential drops within discretized current collector elements without superimposition of thermal effects.

\section{Acknowledgment}

The presented work was supported by the Bavarian Ministry of Economic Affairs and Media, Energy and Technology under the auspices of the EEBatt project and the German Federal Ministry of Education and Research (funding reference number 03X4633A) and Singapore National Research Foundation 
(NRF) through its Campus for Research Excellence and Technological Enterprise (CREATE) program,

[1] B. Scrosati, J. Garche, Lithium batteries: Status, prospects and future, Journal of Power Sources 195 (9) (2010) 2419-2430.

[2] P. Keil, A. Jossen, Charging protocols for lithium-ion batteries and their impact on cycle life-An experimental study with different 18650 high-power cells, Journal of Energy Storage 6 (2016) 125-141.

[3] A. N. Jansen, D. W. Dees, D. P. Abraham, K. Amine, G. L. Henriksen, Low-temperature study of lithium-ion cells using a LiySn micro-reference electrode, Journal of Power Sources 174 (2) (2007) 373-379.

[4] V. Zinth, C. von Lüders, M. Hofmann, J. Hattendorff, I. Buchberger, S. Erhard, J. Rebelo-Kornmeier, A. Jossen, R. Gilles, Lithium plating in lithiumion batteries at sub-ambient temperatures investigated by in situ neutron diffraction, Journal of Power Sources 271 (2014) 152-159.

[5] D. Aurbach, B. Markovsky, A. Rodkin, M. Cojocaru, E. Levi, H.-J. J. Kim, An analysis of rechargeable lithium-ion batteries after prolonged cycling, Electrochimica Acta 47 (12) (2002) 1899-1911.

[6] D. P. Abraham, J. Liu, C. H. Chen, Y. E. Hyung, M. Stoll, N. Elsen, S. MacLaren, R. Twesten, R. Haasch, E. Sammann, I. Petrov, K. Amine, G. Henriksen, Diagnosis of power fade mechanisms in high-power lithiumion cells, Journal of Power Sources 119-121 (2003) 511-516.

[7] K. Onda, T. Ohshima, M. Nakayama, K. Fukuda, T. Araki, Thermal behavior of small lithium-ion battery during rapid charge and discharge cycles, Journal of Power Sources 158 (1) (2006) 535-542.

[8] T. Waldmann, G. Geramifard, M. Wohlfahrt-Mehrens, Influence of current collecting tab design on thermal and electrochemical performance of cylindrical Lithium-ion cells during high current discharge, Journal of Energy Storage 5 (2016) 163-168. 
[9] T. Waldmann, G. Bisle, B.-I. Hogg, S. Stumpp, M. A. Danzer, M. Kasper, P. Axmann, M. Wohlfahrt-Mehrens, Influence of Cell Design on Temperatures and Temperature Gradients in Lithium-Ion Cells: An In Operando Study, Journal of the Electrochemical Society 162 (6) (2015) A921-A927.

[10] M. Klett, R. Eriksson, J. Groot, P. Svens, K. Ciosek Högström, R. W. Lindström, H. Berg, T. Gustafson, G. Lindbergh, K. Edström, Non-uniform aging of cycled commercial LiFePO4//graphite cylindrical cells revealed by post-mortem analysis, Journal of Power Sources 257 (2014) 126-137.

[11] G. Zhang, C. E. Shaffer, C.-Y. Wang, C. D. Rahn, In-Situ Measurement of Current Distribution in a Li-Ion Cell, Journal of the Electrochemical Society 160 (4) (2013) A610-A615.

[12] G. Zhang, C. E. Shaffer, C.-Y. Wang, C. D. Rahn, Effects of Non-Uniform Current Distribution on Energy Density of Li-Ion Cells, Journal of the Electrochemical Society 160 (11) (2013) A2299-A2305.

[13] P. J. Osswald, S. V. Erhard, J. Wilhelm, H. E. Hoster, A. Jossen, Simulation and Measurement of Local Potentials of Modified Commercial Cylindrical Cells, Journal of The Electrochemical Society 162 (10) (2015) A2099A2105.

[14] S. V. Erhard, P. J. Osswald, J. Wilhelm, A. Rheinfeld, S. Kosch, A. Jossen, Simulation and Measurement of Local Potentials of Modified Commercial Cylindrical Cells, Journal of The Electrochemical Society 162 (14) (2015) A2707-A2719.

[15] P. Osswald, S. Erhard, A. Noel, P. Keil, F. Kindermann, H. Hoster, A. Jossen, Current density distribution in cylindrical Li-Ion cells during impedance measurements, Journal of Power Sources 314 (2016) 93-101.

[16] I. Bloom, J. Christophersen, K. Gering, Differential voltage analyses of high-power lithium-ion cells, Journal of Power Sources 139 (1-2) (2005) 304-313. 
[17] J. R. Dahn, Phase diagram of LixC6, Physical Review B 44 (17) (1991) 9170-9177.

[18] A. K. Padhi, K. . Nanjundaswamy, J. B. Goodenough, Phospho-olivines as Positive-Electrode Materials for Rechargeable Lithium Batteries, Journal of The Electrochemical Society 144 (4) (1997) 1188.

[19] M. Fleckenstein, O. Bohlen, M. A. Roscher, B. Bäker, Current density and state of charge inhomogeneities in Li-ion battery cells with $\mathrm{LiFePO} 4$ as cathode material due to temperature gradients, Journal of Power Sources 196 (10) (2011) 4769-4778.

[20] D. M. Bernardi, J.-Y. Go, Analysis of pulse and relaxation behavior in lithium-ion batteries, Journal of Power Sources 196 (1) (2011) 412-427.

[21] Y.-R. Zhu, Y. Xie, R.-S. Zhu, J. Shu, L.-J. Jiang, H.-B. Qiao, T.-F. Yi, Kinetic study on LiFePO4-positive electrode material of lithium-ion battery, Ionics 17 (5) (2011) 437-441.

[22] B. Wu, V. Yufit, M. Marinescu, G. J. Offer, R. F. Martinez-Botas, N. P. Brandon, Coupled thermalelectrochemical modelling of uneven heat generation in lithium-ion battery packs, Journal of Power Sources 243 (2013) $544-554$.

[23] F. M. Kindermann, A. Noel, S. V. Erhard, A. Jossen, Long-term equalization effects in Li-ion batteries due to local state of charge inhomogeneities and their impact on impedance measurements, Electrochimica Acta 185 (2015) 107-116. 